\title{
Hypoplastic right ventricle syndrome variability. Critical pulmonary stenosis and coronary fistula: Case report
}

\author{
Variabilidad en el síndrome de ventrículo derecho hipoplásico. Estenosis pulmonar crítica \\ y fístula coronaria: reporte de caso
}

\author{
María E. Sandoval-Sandoval', Laura R. Chávez-Priego', José A. García-Montes², and \\ Clara A. Vázquez-Antona ${ }^{1 *}$ \\ ${ }^{1}$ Department of Pediatric Echocardiography; ${ }^{2}$ Department of Pediatric Hemodynamics. Instituto Nacional de Cardiología Ignacio Chávez, \\ Mexico City, Mexico
}

The spectrum of hypoplastic right ventricle is broad and challenging, since, depending on its anatomical variability and functionality, appropriate treatment will be decided.

We present the case of a 15-month-old asymptomatic female infant, who had been assessed in a follow-up visit for cyanosis with oxygen saturation of $70 \%$, and for this reason she was referred to our institution. Transthoracic echocardiogram showed significant hypoplasia of both the tricuspid ( $Z$-3.49) and pulmonary valve $(Z-7.43)$, with dilated right ventricle (DRV $Z$ +3.08); on 4-chamber Doppler image, systolic-diastolic flow was observed at the tricuspid annulus lateral wall that ran into the right ventricle, as well as right coronary artery dilatation $(Z+7.8)$, suggestive of coronary artery fistula (Fig.1), and critical pulmonary stenosis, predominantly valvular, with $122-\mathrm{mmHg}$ maximum gradient (Fig.1). Cardiac catheterization was performed in order to place a stent in the right ventricular outflow tract, leaving a residual gradient of $43 \mathrm{mmHg}$; closure of the coronary artery fistula was attempted, which was unsuccessful due to its size (Fig. 2).

The purpose of presenting this case is to show the broad spectrum of hypoplastic right ventricle syndrome presentation, this time with two infrequent associations such as right ventricle dilation in the presence of tricuspid and pulmonary valves hypoplasia with critical pulmonary stenosis and right coronary artery fistula. We assume that this association is not random, and that it has a predisposing factor according to the embryonic bases of heart disease and another triggering factor that depends on the underlying pathophysiology ${ }^{1}$.

For a ventricle to be considered hypoplastic, it must have a tripartite constitution, with an inlet, a trabecular and an outlet portion, but at least two of them are found to be hypodeveloped ${ }^{2}$; generally, it occurs with pulmonary valve atresia and in a lower number cases with stenosis. The size of the tricuspid annulus has been reported to be related to right ventricular dimensions ${ }^{2}$, which was not observed in the case herein presented. Regarding the association of right coronary artery fistula, we consider that the presence of tricuspid and pulmonary hypoplasia with critical stenosis favored communications between the primitive sub-epicardial vascular network and intramyocardial sinusoids, which under normal conditions do not come into contact, since when the vasculogenesis process is completed, myocardial compaction occurs, with the disappearance of primitive sinusoids and appearance of coronary circulation. To the best of our knowledge, the occurrence

\section{Correspondence:}

${ }^{*}$ Clara A. Vázquez-Antona

E-mail: vazquezantona@gmail.com
Date of reception: $15-06-2020$

Date of acceptance: 19-08-2020

DOI: 10.24875/ACME.M21000209
Available online: 19-07-2021

Arch Cardiol Mex (Eng). 2021;91(2):235-236 www.archivoscardiologia.com 2604-7063 / C 2020 Instituto Nacional de Cardiología Ignacio Chávez. Published by Permanyer. This is an open access article under the CC BY-NC-ND license (http://creativecommons.org/licenses/by-nc-nd/4.0/). 


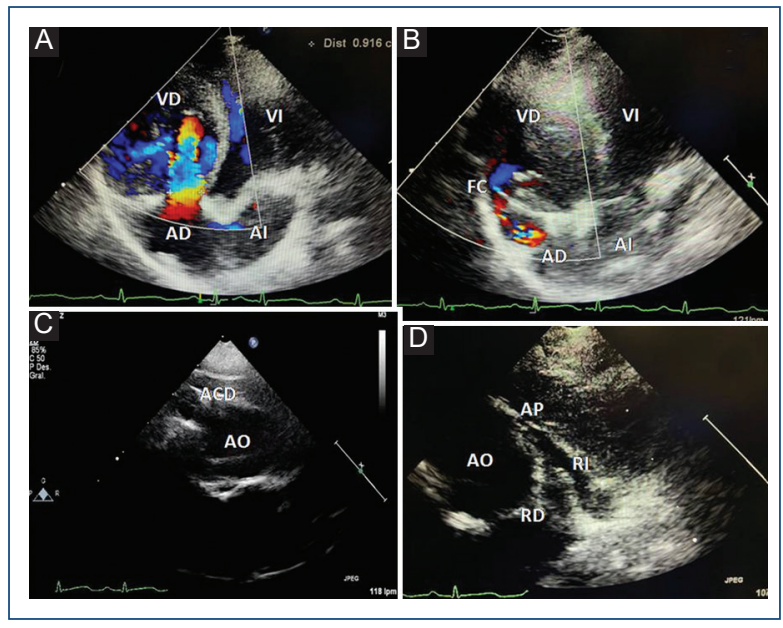

Figure 1. Transthoracic echocardiography images. A: 4-chamber apical color view showing tricuspid annulus hypoplasia and right ventricle dilation. B: 4-chamber apical color view with posterior angulation showing coronary artery fistula abnormal flow lateral to the tricuspid annulus draining into the right ventricle (Video 1). C: parasternal short axis view showing the aorta at the center and origin of the dilated right coronary artery. D: parasternal short axis view showing hypoplasia of the pulmonary artery and pulmonary branches, which are confluent, with stenosis at their origin. ACD: right coronary artery; $\mathrm{AD}$ : right atrium; $\mathrm{Al}$ : left atrium; $\mathrm{AO}$ : aorta; $\mathrm{AP}$ : pulmonary artery; $\mathrm{FC}$ : coronary artery fistula; RD: pulmonary artery right branch; RI: pulmonary artery left branch; VD: right ventricle; VI: left ventricle.

and prevalence of coronary artery fistulae in patients with pulmonary stenosis is rare ${ }^{3}$. Aggarwal et al. ${ }^{4}$ reported an incidence of coronary artery fistulae of $14 \%$ in newborns with critical pulmonary stenosis, associating it with small tricuspid annuli and lower development of the ventricular cavity and pulmonary valve, with most of these cases having small fistulae.

As for the right ventricular dilation shown by this patient, we believe that it may be secondary to the volume overload caused by the arteriovenous shunt produced by the fistula and that, despite having an apparently developed ventricle, abnormalities of the right ventricular myocardial architecture persist, which together with tricuspid hypoplasia prevent biventricular correction.

\section{Funding}

None.

\section{Conflicts of interest}

None.

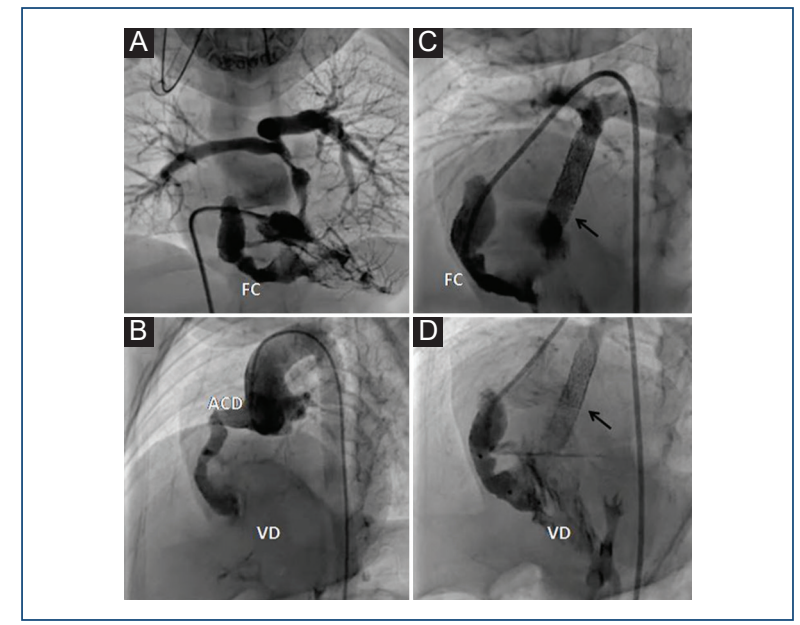

Figure 2. Angiographic images. A: right ventriculography on anteroposterior projection with cranial angulation, where severe pulmonary stenosis with valvular annulus and pulmonary trunk hypoplasia is observed, with slight stenosis at the branches origin and, by counter-flow, filling of the coronary artery fistula, with ectatic, tortuous right coronary artery, as well as with areas of aneurysm, which is corroborated in the following images. B: left axial projection aortography. C: With the passage of the catheter towards the fistula, the stent is observed at the right ventricular outflow tract and the pulmonary artery (arrow). D: placement of a Vascular Plug II-type device for closure of the fistula, still with slight shunt with the right ventricle. ACD: right coronary artery; FC: coronary artery fistula; VD: right ventricle.

\section{Ethical disclosures}

Protection of human and animal subjects. The authors declare that no experiments have been performed on humans or animals for this research.

Confidentiality of data. The authors declare that no patient data appear in this article.

Right to privacy and informed consent. The authors declare that no patient data appear in this article.

\section{References}

1. Rangel $A$, Muñoz L, Solorio S. Fístulas arteriovenosas coronarias múltiples. ¿Azar o predeterminación? Arch Cardiol Mex. 2003;73:31-7.

2. Muñoz L, Galindo M, Kuri M, Epinola N. Hipoplasia ventricular derecha. Estudio morfométrico y morfológico. Arch Cardiol Mex. 2007;77:181-93.

3. Verdini D, Vargas D, Kuo A, Ghoshhajra B, Kim P, Murillo H, et al. Coronary-pulmonary artery fistulas: a systematic review. J Thorac Imaging. 2016;31:380-90

4. Aggarwal V, Mulukutla V, Maskatia S, Justino H, Mullins C, Qureshi A Outcomes after balloon pulmonary valvuloplasty for critical pulmonary stenosis and incidence of coronary artery fistulas. Am J Cardiol. 2018;121:1617-23 